\title{
Modern Trends in Airport Self Check-in Kiosks
}

\section{Jarmila Sabatová ${ }^{1 *}$, Jozef Galanda ${ }^{1}$ František Adamčík ${ }^{2}$, Martin Jezný ${ }^{3}$, Radoslav Šulej ${ }^{1}$}

\author{
${ }^{1}$ Department of Aerodynamics and Simulations, Faculty of Aeronautics, Technical University of Košice, Košice, \\ Slovak Republic \\ ${ }^{2}$ Department of Avionics, Faculty of Aeronautics, Technical University of Košice, Košice, Slovak Republic \\ ${ }^{3}$ Airport Kosice, a.s., Košice, Slovak Republic \\ *Corresponding author: Technical University of Košice, Faculty of Aeronautics, Department of Aerodynamics and \\ Simulations, Rampova 7, 04121 Košice, Slovak Republic, Email: jarmilasabatova@gmail.com
}

\begin{abstract}
Due to maintain the flow of the check-in process of air passengers, it is essential that services that ensure this process have been carried as quickly and effectively. One of the major current problems in this area is the efficiency of clearance of a large number of passengers over the check-in counters. By the gradual development of so-called self check-in services eventually delegate some activities in check-in process to passengers and the entire clearance process to speed up. In this article the authors deal with current state of the use of self check-in services in the world and predict the expected evolution of these services in the future. Subsequently, the authors present a new design of self-service kiosk and graphical user interface (GUI) of application such self-service check-in kiosk based on the analysis of the functions and features of similar solutions available on the market and with considering all currently known IATA requirements and the criteria relating to disabled passengers in order to lighten the load check-in counters and thereby accelerated the clearance of the passenger at the airport. The aim of the authors was to create a cost competitive solution offering such new features and services that do not offer other solutions, with an emphasis on improving the efficiency of the check-in process of passengers at the airport.
\end{abstract}

Keywords

Air transport process - Booking — Graphical user interface — Kiosk — Self check-in

\section{Introduction}

Check-in is a first form of contact with the passenger services at the airport. Self services are focused on speeding up the whole dispatching process of passengers. In present, the methods of dispatching includes: dispatch via a computer, a mobile phone and a self-service kiosk. The aim was to create a graphical user interface that is designed according to the new trends in this field. Air transport process can be charac- terized as the sum of specific levels, which passengers pass during the use of the entire air transport. Air-transport process consists of activities that logically follow each other. This process begins with transportation to the airport followed by clearance at check-in, immigration and customs counter and followed by screening passengers and his baggage at airport. In the next stage the passenger is waiting in so called a sterile space (the space for passengers and the baggage after screen- 
ing process) followed by passing through the gate followed by checking of passenger's boarding pass. The final step of the Air-transport process is transportation and boarding to the aircraft and seating passenger on the chosen place [1].

Check-in process begins at the entrance of passengers in the airport space. Publication IATA Handling Manual includes the whole check-in operation [1]. The aim of the check-in is to control the passengers and their luggage. The aim is to secure entry only to those passengers who hold personal, visa and health documents. The passengers must have a confirmed booking and also paid travel on the entire flight. The passengers registered and hand baggage must be in sufficient number, volume and weight, which corresponds to reimburse travel and responsibility of safety regulations Self-service technologies contribute to increasing the effectiveness and efficiency of airports and airlines. Although the web check-in is also popular form of dispatch, the mobile check-in has become a more attractive way of dispatch.

The global survey of IT Trends Survey from years 2014 and 2015 was meant to explore new trends and technologies in the aerospace industry in the incoming years. The result is an assumption that in 2017 the number of people who use mobile dispatch increase fivefold. One reason is that the number of owners of Smartphone's is rapidly increasing [2, 3].

Figure 1 shows that mobile dispatch becomes definite favorite for the future. It is followed by dispatch via selfservice kiosk and then web check-in.

The benefits of self-check-in services considered on the classic method of dispatch can be viewed from several perspectives which are the passengers, the airports and an airline. If we take a look at this benefits from the view of customers. This is mainly saving a time, because the queue on the airports is smaller. The next are: more personal control, choice of certain services (seat in a plane) or less mistakes in the flight details. Self check-in for the airport also offers a number of advantages for example, better usage of airport space. In association with more free space, we can clearly see a business opportunity for new potential investors. The benefits of self check-in for airlines are in reducing operating and labor costs [4].

Although the check-in kiosks are in use for quite some time, there are always some areas that need improvement, yet. At the airports are kiosks from different airlines, which could

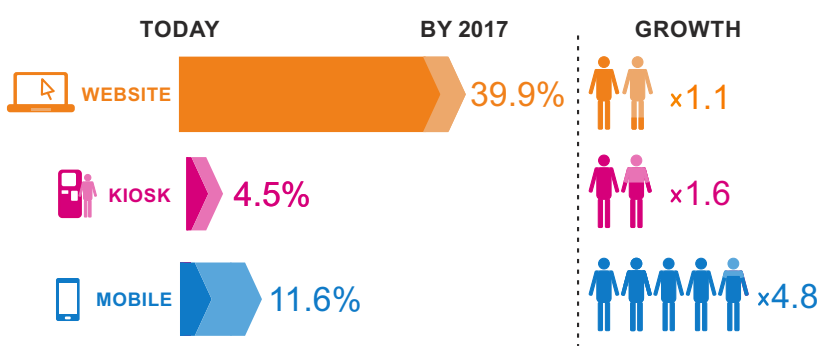

Figure 1. Percentage evaluation of total sales through new technologies [3]. cause chaos for the passengers. Location of self check-in kiosks in the terminals is also often poorly organized, and it may be hard to reach places which are not visible for the passengers [4].

Figure 2 shows that the self check-in process is longer like a standard dispatch, because we must check-in our baggage alone. It is a mistake because time which is spent at the checkin counter is much longer than dispatch via self check-in kiosk. Check-in agent must find passenger's booking in the system, assigns a place on the plane for us, weight a baggage and sign it into the system. Finally, he must prints a boarding pass and a baggage tags [4].

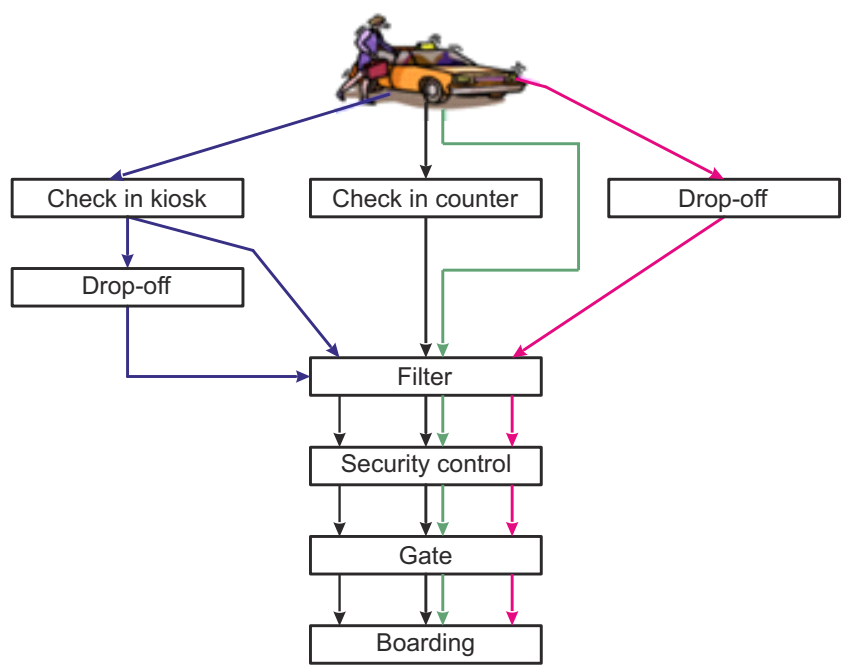

Figure 2. Dispatch of passengers via the kiosk and check-in counters.

\section{Functions and features of self-service devices}

In the Conventional type of check-in environment, the overall throughput of the system can be constrained by a number of factors. The most likely causes of throughput limitation are the productivity of the ticket agents, the staffing levels established by the airline management, or the total ticket counter positions available to the airline. CUTE (Common User Terminal Equipment), the facilities at the airports are shared between the airlines to reduce the space and resources required These systems are known as "agent- facing" systems, because they are used by the airline agents to manage the passenger check-in and boarding process [5].

The primary function of a self-service kiosk (Fig. 3) is represent the customer service. IATA has defined two standards for Common Use at the airports. The first is the CUSS (Common Use Self Service), which is intended to provide operations directly on Customers self-service devices. The second is CUPPS (Common Use Passenger Processing Systems), which is primarily intended for check-in agents at check-in counters, gates and other areas at the airport. The 
aim of the IATA is to merge advantages of CUSS and CUPPS into one standard [6].

All self-service kiosks must comply with the four principles in accordance the IATA requirements. There is a random selection of the operating system and vendors. For kiosks it do not mention any specific type of processor, but the kiosk hardware standards should not be limited on one specific device. Hardware equipment of every kiosk is made up of a touch screen, a scanner passport, a credit card reader and a printer for baggage tags and boarding cards. Without these components they would be useless. The only IATA requirement on software solutions for dispatch is independency of platform on self services and applications. This means that they must support multiple concurrent applications [6].

ADA (Americans with Disabilities Act) set height requirements for self-service kiosks for disabled passengers. The self-service kiosk must be granted access and also parallel side impact without obstacles. Height should not be greater than $122 \mathrm{~cm}$ but less than $38 \mathrm{~cm}$. The display of device must be in an amount which is suitable for disabled passengers [7].

\subsection{Hardware design of self-service kiosk}

On Based of good and long-term cooperation with Kosice airport we decided that the self-service device for which we processed the proposal will be located in this airport. Airport staff also gave to us many valuable tips and practical experience during the design and implementation of the kiosk.

When we had created self-service kiosk, we thought of disabled passengers who need adjust a height. The height of the whole device will be adjusted based on the needs of the passengers. If a passenger suffers a visual impairment can be used hands-free. The whole process will be made available to them in audio recording. Therefore, our device does not contain the classical keyboard, but only a touch screen. Our kiosk includes a printer for baggage tags and boarding cards. We offer more options to how confirm our booking in our kiosk. It can be made through the passport, credit card, loyalty card, or scan the code on the e-ticket. Therefore, the self check-in kiosk needs on these components specific allocated

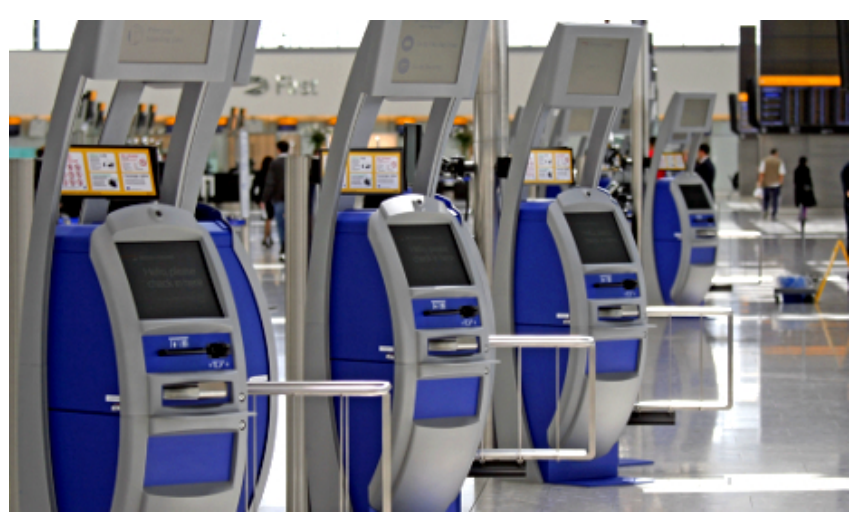

Figure 3. Dispatch of passengers via the kiosk and check-in counters [8].

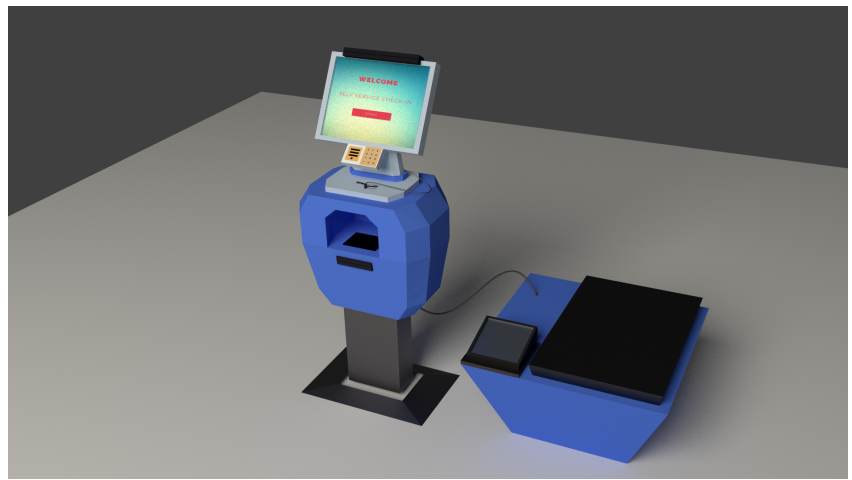

Figure 4. The design of self check-in kiosk.

readers. Over $19 \mathrm{inch}$ touch screen is positioned reader with a magnetic strip. Besides this we offer a contactless terminal for credit cards. In this proposal we also have the choice of back-lighting and other accessories which are the part of the kiosk. The new component is a baggage scanner to determine a weight and to print baggage tags. This scanner includes a custom display which is giving us final weight. Figure 4 shows the final 3D visualization of self check-in kiosk what we designed.

\section{Design of graphical user interface for self-service devices}

We have designed user interface based on analyses of the functions and features of similar solutions available on the market and with considering the requirements of IATA. Our facility respect all currently known IATA requirements and the criteria relating to disabled passengers.

Our vision about selection of reservation type had ranged in two ways. The first way was ability to manually enter a booking number. This option might be for the passenger more difficult, because while he is writing he can make a mistake. On the other hand, the system connection with other distribution systems is faster and therefore it is better choice. The second option is to scan documents. For this variant it is important to have all of the necessary hardware equipment's. With the software design we introduced new services that should be offered in present kiosk. In our work we integrate these new services.

\subsection{The group dispatch}

At present, only very few airlines offers option for passengers to check more than one person. These cases are solved with standard dispatch at check-in counters. Process of validation data for the group is different than an individual. The group must give also physical condition of individual passengers, see Fig. 5.

The group dispatch has a lot more changes than the dispatch of the individual. Another example is the choice of location in the aircraft. Seats in an aircraft for a group is determined by the choice of passenger name. It is marked in 
green color. In our case, the last passenger is a child under two year, therefore he has not assigned seat in the plane. Child sit on knees one from passenger of the group. Assignment a seat for the group dispatch you can see in Fig. 6.

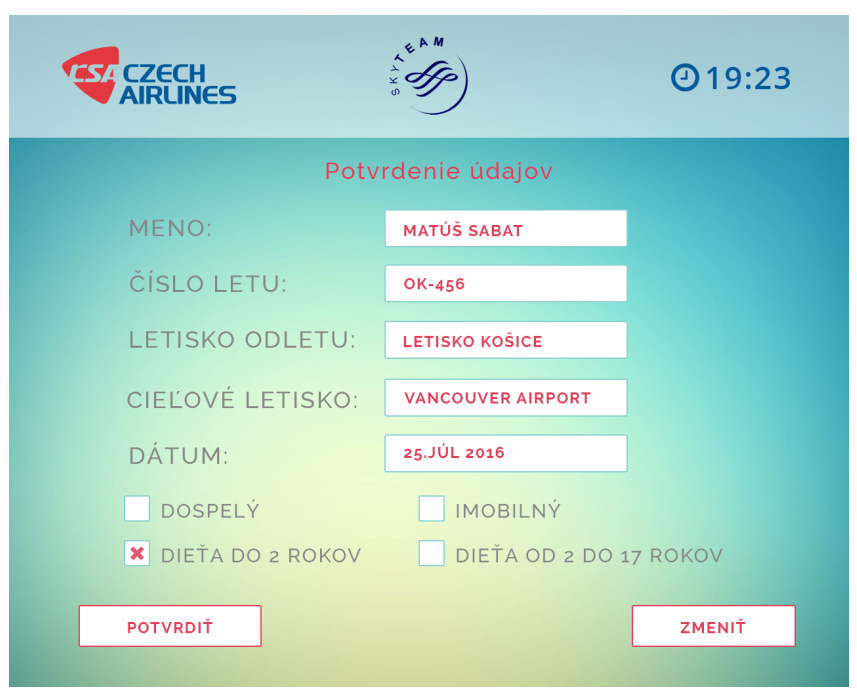

Figure 5. The group dispatch.

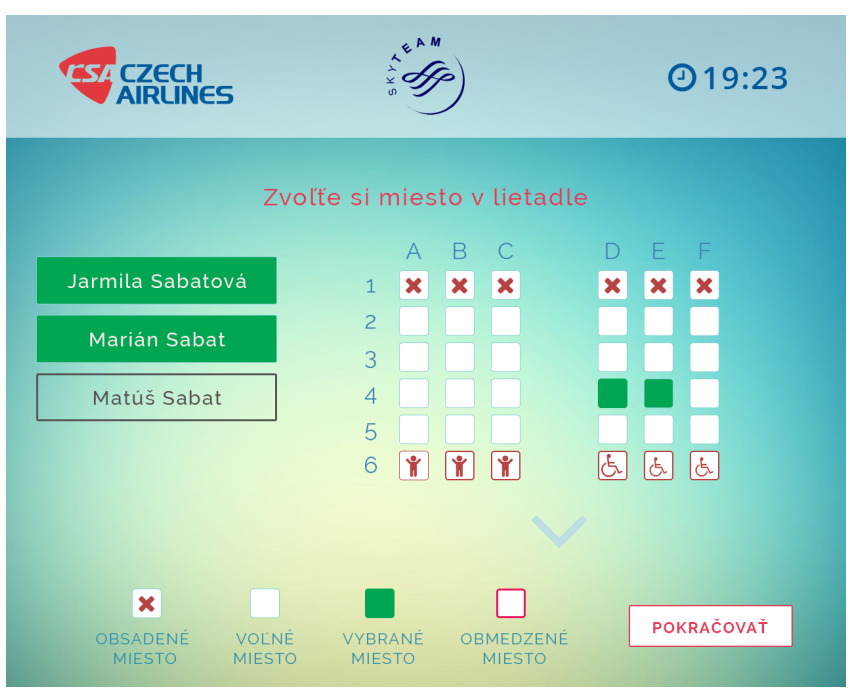

Figure 6. Assignment a seat for the group dispatch.

\subsection{Assistance}

In our proposal, we had taken a deeper look at the passengers with health restrictions. When we are offering assistance, we took note of the fact that to check unaccompanied minors. Assistance services we cover the area of children up to two years, when we offered babies packet and baby meal or children meal. In the picture we can see the offer of assistance to the group dispatch.

\subsection{Change traveling class for a fee}

This service offers only one airline, yet. After using this service, the passenger is obliged to pay the price for change of travel class. This service according to our studies so far provide only one company namely Air Canada. It offers a choice of only three classes, namely: Economy, Business and First Class. Each class is defined by certain properties. It is only on the passenger who can choose a cheaper or more expensive alternative. Economy class offers limited services on board, seats are smaller and closer and in many cases the passengers have to pay for meals or snacks. Business and First Class are often confused, because some airlines, such as Southwest, do not provide first class. Both of these classes have seats adjustable into a horizontal position with private facilities and sufficient spacing. In the first class the passengers usually required better food and alcohol than those in Business Class. In both classes however applies that these services are free. Another advantage of the first class is more attention from the cabin crew dedicated to passengers. Travel class can be changed depending on the conditions of the flight [9].

If a passenger wants to amend the class must reckon with surcharges. Figure 7 shows the possibility of changing offered travel classes.

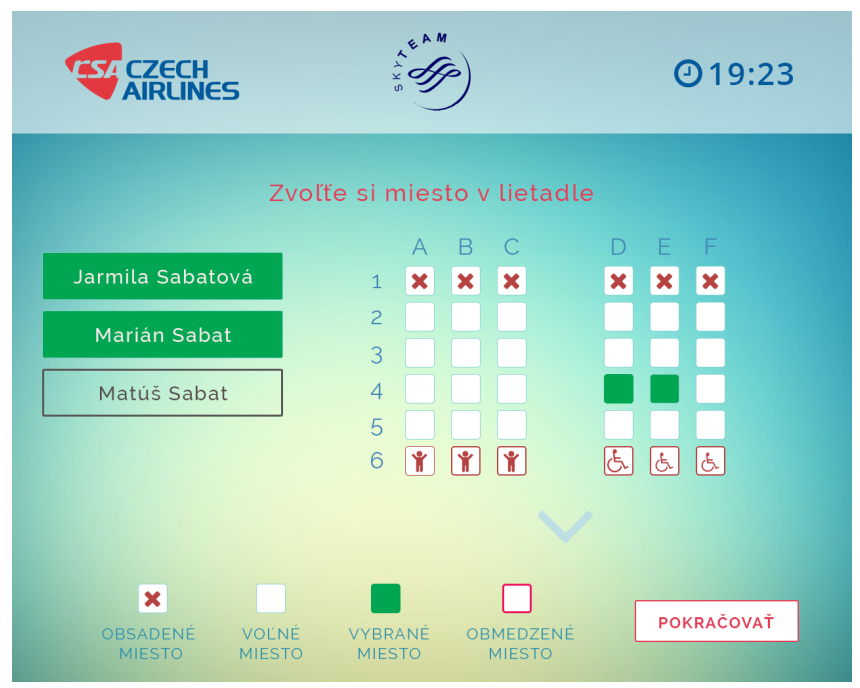

Figure 7. Transportation of a specific type of baggage.

\subsection{Partially baggage check-in}

By using an external luggage scanner the passenger can weigh and check in his luggage himself. When exceeding the luggage limit, the passenger shall to pay an additional fee. Its height is determined by the number of exceedances kilograms. In our proposal passengers will pay for the weight limit is exceeded immediately after the detection of the offense, see Fig. 8.

\subsection{Special kinds of baggage}

In our proposal we offer other traditional services like choice seat in the plane and transport some of the special kinds of baggage. Figure 9 shows that we include transport of the animals, sporting weapons, musical instruments and bikes. This option to check passenger's pet have any airline, yet. 
Other services which the airlines offered are associated with dispatch of baggage. Before printing boarding card and baggage tags we offered settlement of payment witch the passenger do. After the whole check-in process passenger can print boarding card and required number of baggage tags.

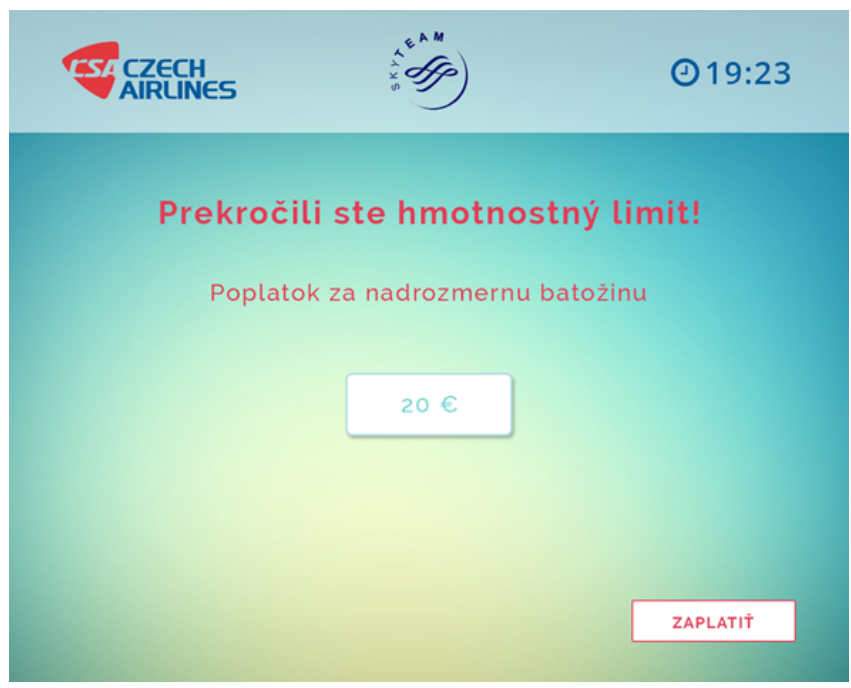

Figure 8. Attention for exceeding the weight limit and the demand for payment.

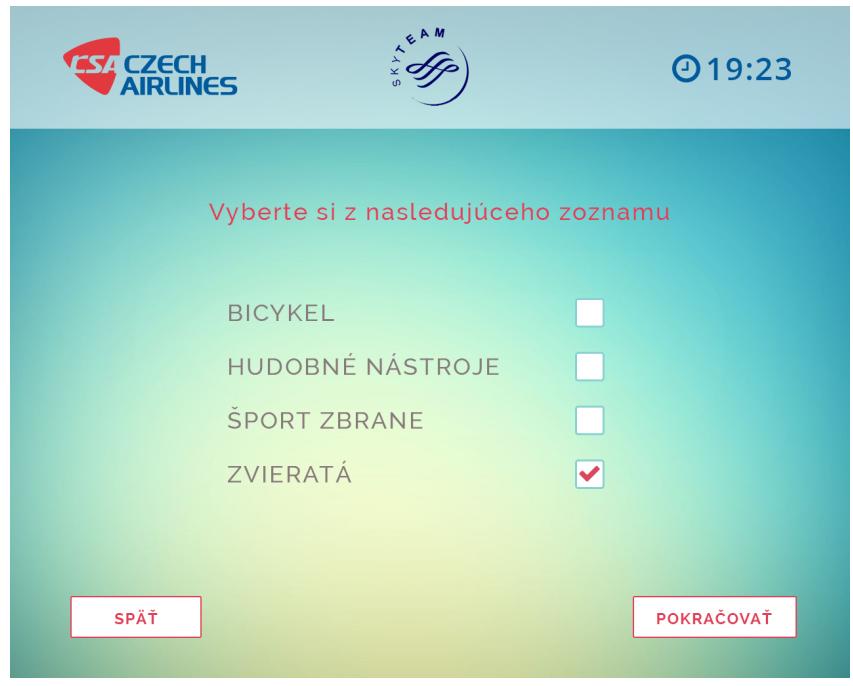

Figure 9. Transportation of a specific type of baggage.

\section{Conclusion}

In pursuing the objective of the present thesis we have tried to propose such a graphical user interface of check-in application that would be as understandable as possible for a passenger. The proposal was based on the analysis of competitive solutions companies that work in this field. After finding the available information, we came to the conclusion that within their offering service are still finding a space for expansion their activities. For this reason, our work becomes unique, because we offer extensive services of the dispatching process. One of the most important services are there, which we offer for the immobile passengers. The introduction of the new hardware elements, we have made faster form of dispatch for them. In the proposal, we also offer the assistance for them. The wider offer of assistance, we also cover services related to children under two years and transportation of unaccompanied children. This prototype of an ideal kiosk has the ability to become desirable for the producers, because it contains elements, which are formed according to the needs of passengers. On the kiosk we implicated a button on assessment of height for the passenger. It is especially designed for the disabled passengers, but it is not a requirement. Another addition is to use a hands-free, whose main task is to convert the audio recording for a visually impaired passenger.

The whole dispatching process can be provided in wider choice of services. These may include a selection of snacks and meals on board. Despite of that we are also expanding transportation of special kinds of baggage, unfortunately we hadn't solved problem with transporting other specific species such as the transportation of human remains and organs for transplantation. These species are very sensitive to it. It is hard for the kiosk to consider a type of everyday baggage. If, in the future, self-service kiosk replaced the check-in counter, the entire check-in process will be based only on the speed and thus the minimum check-in time may be shorter. With shortening the time of check-in are closely related other aspects such as more customers, more flights, and completely new sort of destinations which we can provide thankfully to these new devices.

\section{Acknowledgments}

This work was supported by the Slovak Research and Development Agency under the contract No. APVV-15-0527 "New generation of departure control system for an airports".

\section{References}

[1] IATA. Airport Handling Manual. International Air Transport Association, 35 edition, 2015. ISBN 978-92-9252458-6.

[2] SITA. 2014 Airline it trends survey, 2014. URL http : / / skift.com/wp-content/uploads/2014/07/ 2014-Airline-IT-Trends-Survey_0.pdf.

[3] SITA. 2015 Airline it trends survey, 2015. URL https://www.sita.aero/globalassets/ microsites/atis-2015/thoughtware/ airline-it-trends-survey-2015.pdf.

[4] E. Adamová. Airport operation management - aplikace na regionální letiště, 2011. URL https: / /www.vutbr.cz/www_base/zav_prace_ soubor_verejne.php?file_id=40013. [Online]. 
[5] Shady G Abdelaziz, Abdelfatah A Hegazy, and Ahmed Elabbassy. Study of airport self-service technology within experimental research of check-in techniques. IJCSI, 7 (3):17, 2010. ISSN 1694-0784. URL http: //ijcsi. org/papers/7-3-1-17-26.pdf. [Online].

[6] IATA. Common use self service (cuss), 2013. URL http://caserver.free.fr/CUSS/IATA_ CommonUseSelfService_TechnicalSpec_ June2013_CUSS_1.3.pdf. [Online].

[7] Americans with Disabilities Act. 2010 ada standards for accessible desig, 2010. URL https://www. ada.gov/regs2010/2010ADAStandards/ 2010ADAStandards_prt.pdf. [Online].

[8] Asfar Electronics KIOSK. Airports, 2013. URL http: / / asfarpay. com/?p=1922. [Online].

[9] TripCase. First class vs. business class: What's the difference, $2013 . \quad$ URL http://travel.tripcase.com/blog/ first-class-vs-business-class/. [Online]. 